\title{
Giardiasis
}

\author{
Corrado Minetti postdoctoral research assistant ${ }^{1}$, Rachel M Chalmers consultant clinical scientist \\ and head of unit $^{2}$, Nick $\mathrm{J}$ Beeching senior lecturer in infectious diseases ${ }^{3}$, Chris Probert professor \\ of gastroenterology ${ }^{4}$, Kenneth Lamden general practitioner ${ }^{5}$
}

${ }^{1}$ Vector Biology Group, Liverpool School of Tropical Medicine, Liverpool, UK; ${ }^{2}$ Cryptosporidium Reference Unit, Public Health Wales Microbiology ABM, Singleton Hospital, Swansea, UK; ${ }^{3}$ Clinical Sciences Group, Liverpool School of Tropical Medicine, Liverpool, UK; ${ }^{4}$ Institute of Translational Medicine, University of Liverpool, Liverpool, UK; ${ }^{5}$ Wingate Medical Centre, Kirkby L33 6YJ, UK

Giardia is a leading but treatable cause of infectious gastroenteritis worldwide, with a reported prevalence of $2-7 \%$ in high income countries and $2-30 \%$ in low income countries. ${ }^{1}$ Giardiasis is included in the World Health Organization Neglected Diseases Initiative owing to its burden and association with poverty. ${ }^{2}$ Its incidence in the United Kingdom is underestimated because of the lack of diagnostic sensitivity of traditional faecal microscopy ${ }^{3}$ and the mistaken belief that it is mostly acquired abroad, so often only people reporting foreign travel are tested. This update discusses the epidemiology, clinical presentation, diagnosis, and management of giardiasis specifically in high income countries.

\section{What is Giardia?}

Giardia lamblia (synonyms $G$ duodenalis and $G$ intestinalis) is a flagellated protozoan. Giardia is transmitted through the ingestion of the infective cyst stage shed in human or animal faeces and might be present in faecally contaminated water, food, or fomites. G lamblia comprises eight genetic "assemblages" (named A to H), of which only A and B cause disease in humans but which can also infect pets, livestock, and wild animals and show potential for zoonotic

transmission. ${ }^{4}$ Figure $1 \Downarrow$ depicts the life cycle and transmission of Giardia. The actively multiplying trophozoite form of the organism hatches from the cyst and attaches to the small intestine (fig $2 \mathrm{a} \Downarrow$ ), ${ }^{5}$ where it induces epithelial inflammation, villous flattening, and diarrhoea due to malabsorption. ${ }^{6-8}$ In the large intestine, the trophozoites differentiate forming new cysts (fig $2 b \Downarrow$ ), which are shed in the faeces and contaminate the environment. Cysts present in faeces can remain viable in a variety of environments, particularly water and at lower temperatures: viability can range from 28 to 84 days in lake or river water ${ }^{9}$ but is reduced in soil $1^{10}$ or cattle slurry. ${ }^{11}$

\section{Who gets giardiasis?}

Box 1 summarises the risk factors for acquisition of Giardia in high income countries. Travel to low income settings is a common risk factor, with the highest risk areas being South Asia and South East Asia, North Africa, the Caribbean, and South America ${ }^{25}{ }^{26}$ Giardia is the most common intestinal pathogen in travellers returning to countries such as the UK with gastrointestinal disorders. ${ }^{25-27}$ However, a case-control study in north west England in 2013 found that $75 \%$ of cases were acquired in the UK. ${ }^{12}$ Between 3000 and 4000 cases are reported annually in England and Wales. ${ }^{28}$ However, detection of cases increased fourfold after the introduction of an enzyme linked immunosorbent assay for the detection of parasite antigens in stools, ${ }^{3}$ and another study estimated there were 50000 community cases of giardiasis between April 2008 and August $2009 .{ }^{29}$ The highest incidence of giardiasis is in under $5 \mathrm{~s}$ and adults aged $25-44$ years $^{3-30}$ : most studies report giardiasis being more common in males, ${ }^{3-21}$ and it is more often reported in late summer and early autumn in temperate regions such as the UK and United States. ${ }^{13} 30$

The source of many infections is unknown but is likely to be person-to-person transmission through exposure to human faeces, including sexual transmission. ${ }^{22}$ In a recent prevalence survey in northwest England, 30\% of households in which a family member had a diagnosis of Giardia had a second person with a stool sample positive for Giardia. ${ }^{31}$ Outbreaks have been reported in daycare centres and custodial institutions, ${ }^{20}{ }^{32}$ favoured by overcrowding and poor hygienic conditions.

\section{When to consider Giardia?}

Giardia infections can be asymptomatic (estimated in 5-15\% of infected people), ${ }^{33}$ but typical symptoms include diarrhoea, 


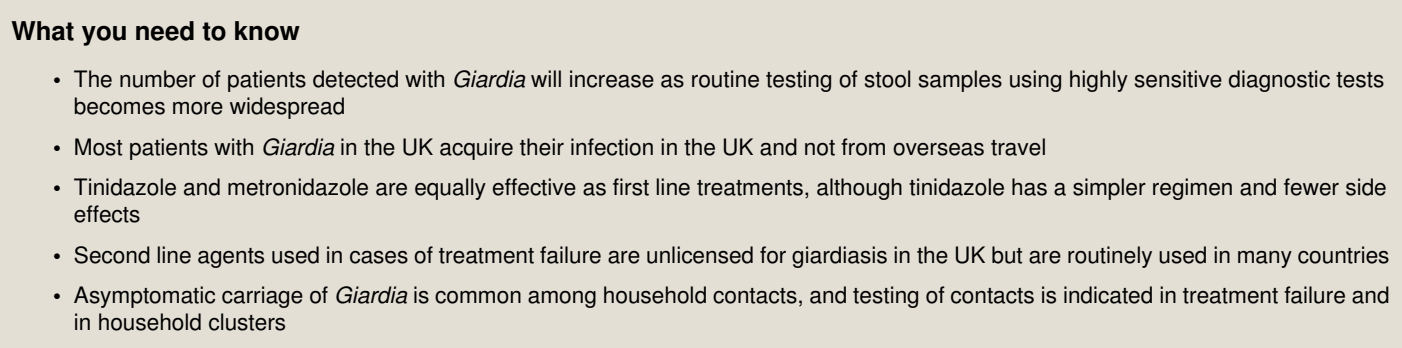

\section{Sources and selection criteria}

We searched PubMed and Medline from 1980 to 2016 for authoritative reviews and research articles on Giardia and giardiasis, which were added to clinical experience, national guidelines, and personal reference collections. We also searched the Cochrane database and reference lists in review articles. Searching was limited to publications in English.

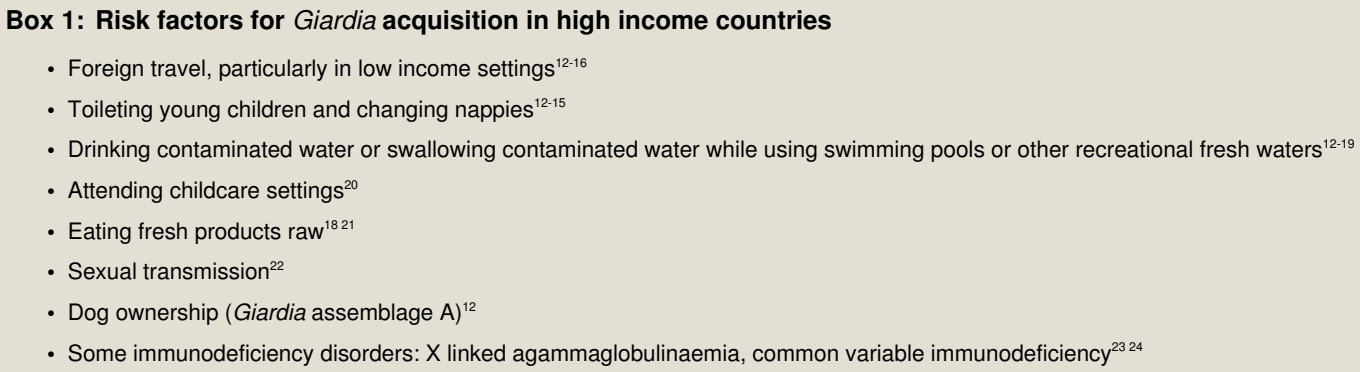

flatulence, abdominal pain, and bloating. ${ }^{33}$ In the early stage of disease, diarrhoea is often explosive, especially in the morning, and the stool is difficult to flush away. Blood in the stool is unusual $^{34}$ and would suggest the presence of another pathogen. Patients sometimes mention "eggy burps" of uncertain cause. Later, the diarrhoea becomes more intermittent, with periods of normal bowel function interspersed with the diarrhoea. Weight loss due to malabsorption occurs in more than $80 \%$ of patients, with a typical loss of $5 \mathrm{~kg}$ in adults over four or more weeks ${ }^{35}$; chronic infection in children might result in failure to thrive. ${ }^{36}$ Intestinal lactase deficiency occurs in up to $40 \%$ of patients with giardiasis and might persist for several weeks after parasite eradication. ${ }^{8}$ This manifests as diarrhoea that is worse after consumption of food or drugs containing lactose. Rarer symptoms include vomiting and fever. ${ }^{33}$ Patients often present with diarrhoea but without typical symptoms of giardiasis and the condition is diagnosed unexpectedly by microbiological examination of a stool specimen. Examination is usually unremarkable apart from features of weight loss, but patients with prolonged symptoms might have features of malabsorption, including pallor due to anaemia. Diagnosis is often delayed, sometimes for months, owing to the insidious onset and relapsing clinical course.

\section{Giardia and irritable bowel syndrome}

The symptoms of giardiasis can resemble irritable bowel syndrome (IBS) ${ }^{37}$ An Italian study of 137 patients investigated in secondary care for IBS or dyspepsia found Giardia in $6.5 \%$ of patients. ${ }^{38}$ However, this finding was not replicated in a larger study ${ }^{39}$ and guidance from the UK National Institute for Health and Care Excellence recommends that faecal testing for ova and parasites is not routinely required to confirm the diagnosis of IBS in people who meet the diagnostic criteria for IBS..$^{40}$ Clinicians should be alert to the possibility of both diagnoses. If there is any doubt, or where there is a relevant exposure history for giardiasis (box 1) consider parasitological examination of a stool sample.

\section{How should suspected giardiasis be investigated?}

Giardiasis is usually diagnosed by laboratory analysis of stool samples (table $1 \Downarrow$ ), either by traditional microscopy (ova, cysts, and parasites (OCP) examination) for visualisation of cysts (or more rarely, trophozoites) or by stool antigen detection assays. ${ }^{3-43}$ The sensitivity of antigen detection assays is superior to microscopy for the diagnosis of giardiasis, but sensitivity between different formats varies (table $1 \Downarrow$ ). Highly sensitive molecular methods (polymerase chain reaction, PCR) that contain parasitology panels are increasingly being used but are not universally available in UK laboratories. ${ }^{44}$ Not all laboratories routinely test stool samples for the microorganism, so specifically request examination of samples for Giardia and document travel or other risk factor history. Owing to variable shedding, three stool specimens (ideally taken two or three days apart) might need to be examined when traditional microscopy is used. If the result is negative, three more specimens should be submitted at weekly intervals, ${ }^{51}$ with a minimum of six negative results required for microscopic exclusion of infection. ${ }^{52}$ There is evidence of improved detection of Giardia in single stool samples using PCR over microscopy of several stool samples or antigen detection assays. ${ }^{46} 47$ At present PCR is only offered as a first line test in a few UK hospital laboratories, and clinicians are advised to discover what tests are available in their local laboratory. In secondary care when giardiasis is highly suspected but stool results are negative, diagnosis can be made through duodenal aspiration and biopsy, which have been shown to detect infection in the absence of cysts on stool microscopy. ${ }^{39}{ }^{48}$ Serological tests for circulating IgG and IgM antibodies to Giardia are not appropriate for clinical diagnosis. 


\section{What treatments are available for giardiasis?}

Unlike many causes of infectious gastroenteritis, giardiasis is treatable (table $2 \Downarrow$ ). Many drugs have been evaluated in reviews and several meta-analyses, ${ }^{53-59}$ including a Cochrane Review in 2012 that examined 19 trials for the effectiveness of the four agents most commonly used to treat giardiasis - metronidazole, tinidazole, albendazole, and nitazoxanide. ${ }^{54}$ Trials included in these reviews are of variable quality and heterogeneous in their location and types and ages of patients included. Some trials have been conducted in low income settings where there is a high prevalence of Giardia infections, and where the resulting partial immunity might alter the clinical picture and observed response to treatment compared with that observed in non-endemic countries or in non-immune people. In most analyses, the 5 nitroimidazoles metronidazole and tinidazole have similar efficacies, with parasitological cure rates and symptom relief in more than $90 \%$ of patients.

\section{Symptomatic patients}

The British National Formulary ${ }^{60}$ currently recommends a five day course of metronidazole as preferred treatment in the UK. Most specialists prescribe a single dose of tinidazole, which is licensed for this indication, has similar efficacy to a multiple dose metronidazole regimen, and is better tolerated. ${ }^{57}$ Repeat either course if unsuccessful, together with exclusion of reinfection (from a household or sexual contact) or lactose intolerance. Advise patients to avoid milk and milk products for at least two weeks (some clinicians advise up to six weeks) to evaluate whether persisting symptoms truly represent treatment failure rather than temporary lactose intolerance. Giardiasis is associated with prolonged symptoms that can have a detrimental impact on quality of life. ${ }^{61}{ }^{62}$ Second line agents such as albendazole or nitazoxanide are routinely available in some countries but are not licensed for the treatment of giardiasis in the UK. Specialist advice is recommended if second line agents are required. Albendazole has similar efficacy to metronidazole and is better tolerated. ${ }^{55}$ Nitazoxanide is more difficult to obtain and more expensive in the UK, and paromomycin is the only second line agent that can be used in pregnancy. Mepacrine (quinacrine) is effective but has numerous side effects and is reserved for management of refractory cases by specialists.

Confirmation of treatment failure is best provided by PCR, which offers improved detection in single stool samples over microscopy. ${ }^{63}$ Treatment success is indicated by complete resolution of symptoms or lack of detection of Giardia DNA by PCR one week after treatment.

Treatment failure might be due to host factors or to true drug resistance, which is well recognised and increasingly common, particularly in travellers returning from South Asia and South East Asia. ${ }^{16-65}$ However, tinidazole or metronidazole should still be used as first line treatment for travellers returning from these areas despite cross resistance between these drugs. ${ }^{65}$ Patients with treatment failure should be discussed with or referred to a specialist, who should exclude underlying problems such as coeliac disease, inherited disaccharidase deficiency, and immunodeficiency disorders, particularly of total and $\operatorname{Ig} \mathrm{A}$ antibody production. ${ }^{23-61}$ Combination treatment with the above agents may be used under specialist care.

A variety of combination treatments are effective, although the evidence is based on observational studies and individual clinician preference. ${ }^{56-69}$ Combinations of albendazole and a 5 nitroimidazole, or nitazoxanide with a second agent, are the usual next steps in the treatment ladder. Paromomycin and mepacrine have specific niches, as already discussed.

\section{Asymptomatic patients}

Asymptomatic carriage of Giardia is common in contacts of cases, and household clusters do occur. In a recent study in north west England, routine testing of all household contacts of 91 primary Giardia cases found a contact positive for Giardia in 27 households (30\%): of the 212 contacts, 41 (19\%) were positive, most of whom were asymptomatic. ${ }^{31}$ In the absence of research as to whether treatment of asymptomatic carriage is effective in curtailing transmission, management is based on expert opinion. ${ }^{53}$ Asymptomatic carriage is generally not treated, but treatment is rational in failed treatment of a case or in household clusters. In these situations a pragmatic alternative may be to offer blind treatment to all household contacts based on their preference. Wider availability of sensitive PCR diagnostic tests may allow a more targeted approach to contact treatment in future.

\section{Can Giardia infection be prevented?}

Individual cases require investigation, usually by environmental health officers, to prevent onward spread and identify likely exposures. In many high income countries, including the UK, surveillance is underpinned by statutory notification of Giardia diagnoses by hospital laboratories to the local public health system. ${ }^{70-72}$ Prevention of secondary transmission is mainly through antiparasitic treatment of cases and advice on the prevention of person-to-person spread through stringent personal hygiene (box 2). Exclusion on the basis of the absence of diarrhoea for 48 hours applies to children in nurseries, food handlers, and those caring for vulnerable adults. ${ }^{73}$

Microbiological evidence of stool clearance is not usually required, but this might be considered in outbreak situations.

Giardia cysts are more resistant to chlorine disinfection than most bacteria, and outbreaks have been reported linked to contaminated mains drinking water, swimming pools, and paddling pools. ${ }^{17}{ }^{19}$ Adherence to guidelines for swimming pool management ${ }^{74}$ reduces the risk of giardiasis to a minimum. Outbreaks due to drinking water are uncommon in the $\mathrm{UK}^{75}$ because of the full treatment of public water supplies (filtration and disinfection), but they are a risk where treatment is inadequate. Travellers should check that water disinfection filters or systems they use are certified to remove Giardia.

We thank numerous clinical colleagues at the Liverpool School of Tropical Medicine and the Hospital for Tropical Diseases, London, for helpful discussions and comments. CM received $\mathrm{PhD}$ funding from Public Health England (PHE). NJB receives partial support from the National Institute of Health Research (NIHR) Health Protection Unit in Gastrointestinal Infections, Farr Institute, University of Liverpool, in partnership with PHE and the Universities of Oxford and of East Anglia. NJB is affiliated with the University of Liverpool. The views expressed are those of the authors and not necessarily those of the NHS, NIHR, Department of Health, or PHE.

Contributors: All authors contributed equally to the preparation of this manuscript. $\mathrm{KL}$ is the guarantor.

Competing interests: We have read and understood BMJ policy on declaration of interests and declare the following: none.

Provenance and peer review: Not commissioned; externally peer reviewed. 


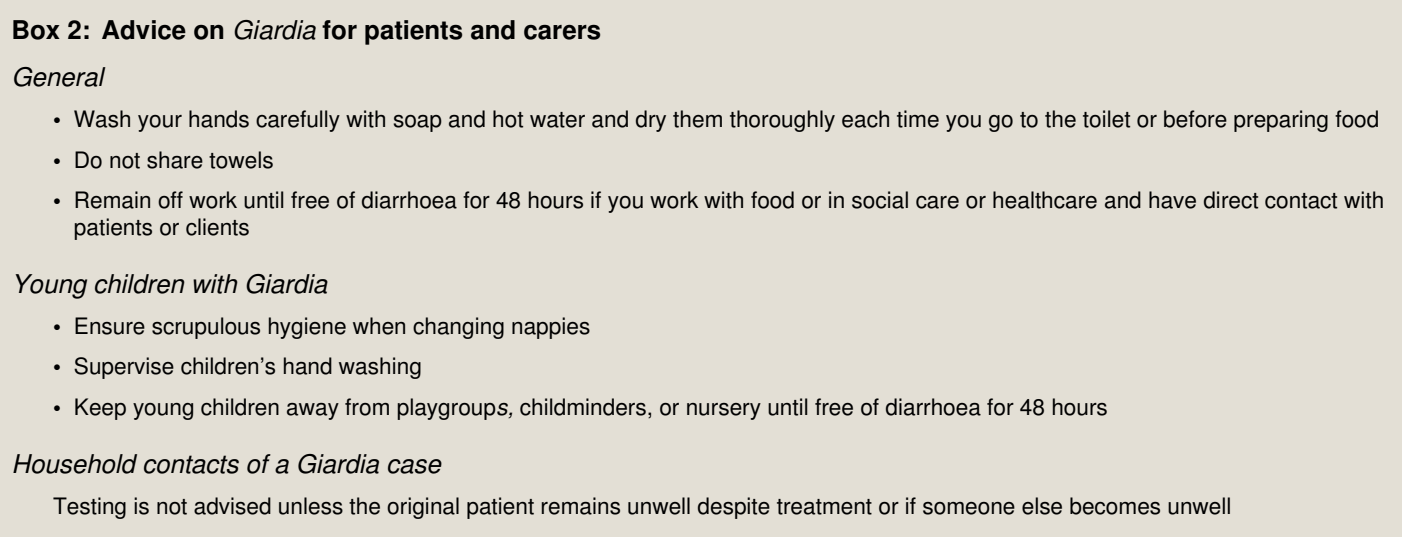

\section{How patients were involved in the creation of the article}

No patients were involved in the creation of this review.

\section{Questions for ongoing and future research}

-What behavioural or immunological factors could explain the excess of giardiasis in males?

- What is the extent of zoonotic transmission risk for Giardia?

- Do different Giardia lamblia genetic assemblages differ in transmission and clinical outcome of disease?

- Is previous exposure to Giardia protective against successive infections in travellers?

- What is the relation between Giardia and irritable bowel syndrome or other post-infectious gastrointestinal disorders?

-Why are some infections refractory to treatment?

- How common is drug resistance and what is the molecular basis of resistance?

- What is the most effective and safe treatment for refractory infections?

- Is treatment of asymptomatic excretors effective in curtailing transmission, and, if so, when should it be offered?

- Is there a role for prebiotics or probiotics in prevention or management of infection?

\section{Education into practice}

Do you request specific Giardia testing in patients presenting with relapsing diarrhoea, negative results on bacterial stool culture, and no history of overseas travel?

\section{Additional educational resources}

Information for healthcare professionals

- Public Health England (www.gov.uk/guidance/giardia)—for surveillance information and epidemiological trends of giardiasis

- US Centers for Disease Control and Prevention (www.cdc.gov/parasites/giardia/audience-health-professionals.html)_for epidemiological information and links to veterinary and environmental aspects of Giardia

Information for patients

- US Centers for Disease Control and Prevention (www.cdc.gov/parasites/giardia/)—provides answers to frequently asked questions about Giardia

- New Zealand Ministry of Health (www.health.govt.nz/your-health/conditions-and-treatments/diseases-and-illnesses/food-and-waterborne-diseases/giardia) — has general information about giardiasis

- Patient website (http://patient.info/health/giardia)—has an information leaflet with preventive advice

- National Travel Health Network and Centre ( $\mathrm{NaTHNaC}$ ) (http://travelhealthpro.org.uk/travellers-diarrhoea/)—provides pre-travel advice, as well as links to country specific advice

- Fit for Travel (www.fitfortravel.nhs.uk/advice/disease-prevention-advice/travellers-diarrhoea.aspx_—provides similar pre-travel advice on hygiene and disease prevention

1 Fletcher SM, Stark D, Harkness J, Ellis J. Enteric protozoa in the developed world: a public health perspective. Clin Microbiol Rev 2012;25:420-49. doi:10.1128/CMR.0503811. pmid:22763633.

2 Savioli L, Smith H, Thompson A. Giardia and Cryptosporidium join the 'Neglected Diseases Initiative'. Trends Parasitol 2006;22:203-8. doi:10.1016/j.pt.2006.02.015. pmid:16545611.

3 Ellam H, Verlander NQ, Lamden K, Cheesbrough JS, Durband CA, James S. Surveillance of giardiasis in Northwest England 1996-2006: impact of an enzyme immunoassay test. Euro Surveill 2008;13:18977.pmid:18801316.

4 Ryan U, Cacciò SM. Zoonotic potential of Giardia. Int J Parasitol 2013;43:943-56. doi:10. 1016/j.jpara.2013.06.001. pmid:23856595
5 Adam RD. Biology of Giardia lamblia. Clin Microbiol Rev 2001;14:447-75. doi:10.1128/ CMR.14.3.447-475.2001. pmid:11432808.

6 Buret AG. Pathophysiology of enteric infections with Giardia duodenalius. Parasite 2008;15:261-5. doi:10.1051/parasite/2008153261. pmid:18814692.

7 Cotton JA, Beatty JK, Buret AG. Host parasite interactions and pathophysiology in Giardia infections. Int J Parasitol 2011;41:925-33. doi:10.1016/j.jppara.2011.05.002. pmid: 21683702 .

8 Farthing MJ. Giardiasis. Gastroenterol Clin North Am 1996;25:493-515. doi:10.1016/ S0889-8553(05)70260-0 pmid:8863037.

9 deRegnier DP, Cole L, Schupp DG, Erlandsen SL. Viability of Giardia cysts suspended in lake, river, and tap water. Appl Environ Microbiol 1989;55:1223-9.pmid:2757381. 
10 Olson M, Guselle N, McAllister TA, et al. Giardia cyst and Cryptosporidium oocyst survival in water, soil, and cattle feces. J Environ Qual 1999;28:1991-6doi:10.2134/jeq1999. $00472425002800060040 x$

11 Grit GH, Bénéré E, Ehsan A, et al. Giardia duodenalis cyst survival in cattle slurry. Vet Parasitol 2012;184:330-4. doi:10.1016/j.vetpar.2011.08.021. pmid:21903330.

12 Minetti C, Lamden K, Durband C, et al. Case-control study of risk factors for sporadic giardiasis and parasite assemblages in North West England. J Clin Microbiol 2015:53:3133-40. doi:10.1128/JCM.00715-15. pmid:26157151.

13 Gray SF, Gunnell DJ, Peters TJ. Risk factors for giardiasis: a case-control study in Avon and Somerset. Epidemiol Infect 1994;113:95-102. doi:10.1017/S0950268800051505 pmid: 8062884

14 Gagnon F, Duchesne JF, Lévesque B, Gingras S, Chartrand J. Risk of giardiasis associated with water supply in an endemic context. Int $J$ Environ Health Res 2006;16:349-59. doi:10.1080/09603120600869265. pmid:16990176.

15 Hoque ME, Hope VT, Kjellström T, Scragg R, Lay-Yee R. Risk of giardiasis in Aucklanders: a case-control study. Int J Infect Dis 2002;6:191-7. doi:10.1016/S1201-9712(02)901104 pmid:12718834.

16 Barrett J, Brown M. Travellers' diarrhoea. BMJ 2016;353:i1937. doi:10.1136/bmj. 1937. pmid:27094342.

17 Baldursson $\mathrm{S}$, Karanis $\mathrm{P}$. Waterborne transmission of protozoan parasites: review of worldwide outbreaks - an update 2004-2010. Water Res 2011;45:6603-14. doi:10.1016/ j.watres.2011.10.013. pmid:22048017.

18 Stuart JM, Orr HJ, Warburton FG, et al. Risk factors for sporadic giardiasis: a case-control study in southwestern England. Emerg Infect Dis 2003;9:229-33. doi:10.3201/eid0902. 010488. pmid:12603995.

19 Karanis $\mathrm{P}$, Kourenti $\mathrm{C}$, Smith $\mathrm{H}$. Waterborne transmission of protozoan parasites: a worldwide review of outbreaks and lessons learnt. J Water Health 2007;5:1-38. doi:10. 2166/wh.2006.002. pmid:17402277.

20 Rauch AM, Van R, Bartlett AV, Pickering LK. Longitudinal study of Giardia lamblia infection in a day care center population. Pediatr Infect Dis J 1990;9:186-9. doi:10.1097/00006454199003000-00008 pmid:2336299.

21 Espelage W, an der Heiden M, Stark K, Alpers K. Characteristics and risk factors for symptomatic Giardia lamblia infections in Germany. BMC Public Health 2010;10:41. doi: 10.1186/1471-2458-10-41. pmid:20105338.

22 Escobedo AA, Almirall P, Alfonso M, Cimerman S, Chacín-Bonilla L. Sexual transmission of giardiasis: a neglected route of spread?Acta Trop 2014;132:106-11. doi:10.1016/j. actatropica.2013.12.025. pmid:24434784.

23 Hermaszewski RA, Webster AD. Primary hypogammaglobulinaemia: a survey of clinical manifestations and complications. Q J Med 1993:86:31-42.pmid:8438047.

24 Agarwal S, Mayer L. Diagnosis and treatment of gastrointestinal disorders in patients with primary immunodeficiency. Clin Gastroenterol Hepatol 2013;11:1050-63. doi:10.1016/j. cgh.2013.02.024. pmid:23501398.

25 Swaminathan A, Torresi J, Schlagenhauf P, et al. GeoSentinel Network. A global study of pathogens and host risk factors associated with infectious gastrointestinal disease in returned international travellers. J Infect 2009;59:19-27. doi:10.1016/j.jinf.2009.05. 008. pmid: 19552961

26 Ross AGP, Olds GR, Cripps AW, Farrar JJ, McManus DP. Enteropathogens and chronic illness in returning travelers. N Engl J Med 2013;368:1817-25. doi:10.1056/ NEJMra1207777. pmid:23656647.

27 McGregor AC, Whitty CJM, Wright SG. Geographic, symptomatic and laboratory predictors of parasitic and bacterial causes of diarrhoea in travellers. Trans $R$ Soc Trop Med Hyg 2012;106:549-53. doi:10.1016/j.trstmh.2012.04.008. pmid:22818743.

28 Public Health England. Giardia: guidance and data. 2014. https://www.gov.uk/guidance/ giardia\#epidemiology.

29 Tam CC, Rodrigues LC, Viviani L, et al. IID2 Study Executive Committee. Longitudinal study of infectious intestinal disease in the UK (IID2 study): incidence in the community and presenting to general practice. Gut 2012;61:69-77. doi:10.1136/gut.2011.238386. pmid: 21708822 .

30 Painter JE, Gargano JW, Collier SA, Yoder JS. Centers for Disease Control and Prevention. Giardiasis surveillance -- United States, 2011-2012. MMWR Suppl 2015;64:15-25.pmid: 25928582.

31 Waldram A, Lamden K, Vivancos R. Asymptomatic giardia Infection: an important source of ongoing transmission within the household in Northwest England, Abst O-22. In: 5 Nations Health Protection Conference. 2015. http://5nations.org.uk/?page id=921

32 Naiman HL, Sekla L, Albritton WL. Giardiasis and other intestinal parasitic infections in a Manitoba residential school for the mentally retarded. Can Med Assoc J 1980;122:185-8.pmid:7363211.

33 Hill DR. Giardia lamblia. In: Gillespie S, Pearson RD, eds. Principles and Practice of Clinical Parasitology. John Wiley \& Sons Ltd, 2001:219-42doi:10.1002/0470842504.ch10.

34 Breathnach AS, McHugh TD, Butcher PD. Prevalence and clinical correlations of genetic subtypes of Giardia lamblia in an urban setting. Epidemiol Infect 2010;138:1459-67. doi: 10.1017/S0950268810000208. pmid:20144251.

35 Nygård K, Schimmer B, Søbstad Ø, et al. A large community outbreak of waterborne giardiasis-delayed detection in a non-endemic urban area. BMC Public Health 2006;6:141. doi:10.1186/1471-2458-6-141. pmid:16725025.

36 Ignatius R, Gahutu JB, Klotz C, et al. High prevalence of Giardia duodenalis Assemblage $\mathrm{B}$ infection and association with underweight in Rwandan children. PLoS Negl Trop Dis 2012;6:e1677. doi:10.1371/journal.pntd.0001677. pmid:22720102.

37 Stark D, van Hal S, Marriott D, Ellis J, Harkness J. Irritable bowel syndrome: a review on the role of intestinal protozoa and the importance of their detection and diagnosis. Int $\mathrm{J}$ Parasitol 2007:37:11-20. doi:10.1016/.jijpara.2006.09.009. pmid:17070814.

38 Grazioli B, Matera G, Laratta C, et al. Giardia lamblia infection in patients with irritable bowel syndrome and dyspepsia: a prospective study. World J Gastroenterol 2006;12:1941-4. doi:10.3748/wjg.v12.112.1941 pmid:16610003.

39 Chew TS, Hopper AD, Sanders DS. Is there a role for routine duodenal biopsy in diagnosing giardiasis in a European population? Scand J Gastroenterol 2008;43:1219-23. doi:10.1080/00365520802101853. pmid:18609157.

40 National Institute for Health and Care Excellence. Irritable bowel syndrome in adults: diagnosis and management. Clinical guideline [CG61]. 2015. https://www.nice.org.uk/ guidance/cg61

41 Halland M, Saito YA. Irritable bowel syndrome: new and emerging treatments. $B M$ 2015;350:h1622. doi:10.1136/bmj.h1622. pmid:26088265

42 Public Health England. UK Standards for Microbiology Investigations B 31: Investigation of specimens other than blood for parasites. Public Health England 2014.https://www. gov.uk/government/uploads/system/uploads/attachment_data/file/343958/B_31i4.1.pdf.
43 McHardy IH, Wu M, Shimizu-Cohen R, Couturier MR, Humphries RM. Detection of intestinal protozoa in the clinical laboratory. J Clin Microbiol 2014:52:712-20. doi:10.1128/ JCM.02877-13. pmid:24197877.

44 Verweij JJ, van Lieshout L. Intestinal parasitic infections in an industrialized country; a new focus on children with better DNA-based diagnostics. Parasitology 2011;138:1492-8. doi:10.1017/S0031182011001211. pmid:21859503.

45 Heyworth MF. Diagnostic testing for Giardia infections. Trans R Soc Trop Med Hyg 2014;108:123-5. doi:10.1093/trstmh/tru005. pmid:24463773.

46 Llewellyn S, Inpankaew T, Nery SV, et al. Application of a Multiplex Quantitative PCR to Assess Prevalence and Intensity Of Intestinal Parasite Infections in a Controlled Clinical Trial. PLoS Negl Trop Dis 2016;10:e0004380. doi:10.1371/journal.pntd.0004380. pmid: 26820626.

47 ten Hove RJ, van Esbroeck M, Vervoort T, van den Ende J, van Lieshout L, Verweij JJ. Molecular diagnostics of intestinal parasites in returning travellers. Eur $J$ Clin Microbiol Infect Dis 2009;28:1045-53. doi:10.1007/s10096-009-0745-1. pmid:19415354.

48 Rosenthal P, Liebman WM. Comparative study of stool examinations, duodenal aspiration, and pediatric Entero-Test for giardiasis in children. J Pediatr 1980;96:278-9. doi:10.1016/ S0022-3476(80)80826-2. pmid:7351595.

49 Soares R, Tasca T. Giardiasis: an update review on sensitivity and specificity of methods for laboratorial diagnosis. J Microbiol Methods 2016;129:98-102. doi:10.1016/..mimet. 2016.08.017. pmid:27546714.

50 Gotfred-Rasmussen H, Lund M, Enemark HL, Erlandsen M, Petersen E. Comparison of sensitivity and specificity of 4 methods for detection of Giardia duodenalis in feces: immunofluorescence and PCR are superior to microscopy of concentrated iodine-stained samples. Diagn Microbiol Infect Dis 2016;84:187-90. doi:10.1016/j.diagmicrobio.2015.11. 005. pmid:26707069.

51 Roberts L, Zeibig EA. Specimen collection and processing. In: Clinical Parasitology - a practical approach. 2nd ed. Elsevier, 2013: 14-40.

52 Public Health England. The PHE national parasitology reference laboratory user manual version 8.0. 2013. https://www.gov.uk/government/uploads/system/uploads/attachment data/file/342388/The_PHE_National_Parasitology_Reference_Laboratory_User_Manual_ v8.pdf

53 Gardner TB, Hill DR. Treatment of giardiasis. Clin Microbiol Rev 2001;14:114-28. doi:10. 1128/CMR.14.1.114-128.2001. pmid:11148005.

54 Granados CE, Reveiz L, Uribe LG, Criollo CP. Drugs for treating giardiasis. Cochrane Database Syst Rev 2012;12:CD007787. doi:10.1002/14651858.CD007787.pub2. pmid: 23235648.

55 Escobedo AA, Ballesteros J, González-Fraile E, Almirall P. A meta-analysis of the efficacy of albendazole compared with tinidazole as treatments for Giardia infections in children. Acta Trop 2016;153:120-7. doi:10.1016/j.actatropica.2015.09.023. pmid:26476393.

56 Escobedo AA, Hanevik K, Almirall P, Cimerman S, Alfonso M. Management of chronic Giardia infection. Expert Rev Anti Infect Ther 2014;12:1143-57. doi:10.1586/14787210. 2014.942283. pmid:25059638.

57 Pasupuleti V, Escobedo AA, Deshpande A, Thota P, Roman Y, Hernandez AV. Efficacy of 5-nitroimidazoles for the treatment of giardiasis: a systematic review of randomized controlled trials. PLOS Negl Trop Dis 2014;8:e2733. doi:10.1371/journal.pntd. 0002733. pmid:24625554.

58 Escobedo AA, Lalle M, Hrastnik NI, et al. Combination therapy in the management of giardiasis: What laboratory and clinical studies tell us, so far. Acta Trop 2016;162:196-205. doi:10.1016/j.actatropica.2016.06.026. pmid:27349189.

59 Solaymani-Mohammadi S, Genkinger JM, Loffredo CA, Singer SM. A meta-analysis of the effectiveness of albendazole compared with metronidazole as treatments for infections with Giardia duodenalis. PLoS Negl Trop Dis 2010;4:e682. doi:10.1371/journal.pntd. 0000682. pmid:20485492.

60 Joint Formulary Committee. British National Formulary. 2016. BMJ Group and Pharmaceutical Press. https://www.evidence.nhs.uk/formulary/bnt/current.

61 Robertson LJ, Hanevik K, Escobedo AA, Mørch K, Langeland N. Giardiasis--why do the symptoms sometimes never stop? Trends Parasitol 2010;26:75-82. doi:10.1016/j.pt.2009. 11.010. pmid:20056486

62 Hanevik K, Wensaas K-A, Rortveit G, et al. Irritable bowel syndrome and chronic fatigue 6 years after giardia infection: a controlled prospective cohort study. Clin Infect Dis 2014;59:1394-400. doi:10.1093/cid/ciu629.

63 van den Bijllaardt W, Overdevest IT, Buiting AG, Verweij JJ. Rapid clearance of Giardia lamblia DNA from the gut after successful treatment. Clin Microbiol Infect 2014;20:0972-4 doi:10.1111/1469-0691.12626. pmid:24655130.

64 Nabarro LEB, Lever RA, Armstrong M, Chiodini PL. Increased incidence of nitroimidazole-refractory giardiasis at the Hospital for Tropical Diseases, London: 2008-2013. Clin Microbiol Infect 2015;21:791-6. doi:10.1016/j.cmi.2015.04.019. pmid: 25975511.

65 Leitsch D. Drug resistance in the microaerophilic parasite Giardia lamblia. Curr Trop Med Rep 2015;2:128-35. doi:10.1007/s40475-015-0051-1. pmid:26258002.

66 Muñoz Gutiérrez J, Aldasoro E, Requena A, et al. Refractory giardiasis in Spanish travellers. Travel Med Infect Dis 2013;11:126-9. doi:10.1016/j.tmaid.2012.10.004. pmid: 23218784.

67 Nash TE, Ohl CA, Thomas E, Subramanian G, Keiser P, Moore TA. Treatment of patients with refractory giardiasis. Clin Infect Dis 2001;33:22-8. doi:10.1086/320886. pmid: 11389490.

68 Mørch K, Hanevik K, Robertson LJ, Strand EA, Langeland N. Treatment-ladder and genetic characterisation of parasites in refractory giardiasis after an outbreak in Norway. $J$ Infect 2008;56:268-73. doi:10.1016/j.jinf.2008.01.013. pmid:18328567.

69 Meltzer E, Lachish T, Schwartz E. Treatment of giardiasis after nonresponse to nitroimidazole. Emerg Infect Dis 2014;20:1742-4. doi:10.3201/eid2010.140073. pmid: 25271363.

70 Department of Health. Health Protection Legislation (England) Guidance 2010. 2010. http://www.dh.gov.uk/en/Publicationsandstatistics/Publications/ PublicationsPolicyAndGuidance/DH_114510

71 Health Protection Scotland. Public Health etc. (Scotland) Act 2008 - Implementation of part 2: notifiable diseases, organisms and health risk states. 2015. http://patient.info/ doctor/notifiable-diseases

72 Public Health Wales. The Health Protection (Notification) (Wales) Regulations 2010. 2010 http://www.legislation.gov.uk/wsi/2010/1546/contents/made

73 PHLS Advisory Committee on Gastrointestinal Infections. Preventing person-to-person spread following gastrointestinal infections: guidelines for public health physicians and environmental health officers. Commun Dis Public Health 2004;7:362-84.pmid:15786582. 
74 World Health Organization. Guidelines for safe recreational water environments - Volume 2: Swimming pools and similar environments. Geneva. World Health Organization 2006. http://www.who.int/water_sanitation_health/bathing/bathing2/en/

75 Smith A, Reacher M, Smerdon W, Adak GK, Nichols G, Chalmers RM. Outbreaks of waterborne infectious intestinal disease in England and Wales, 1992-2003. Epidemiol Infect 2006;134:1141-9. doi:10.1017/S0950268806006406. pmid:16690002.
Published by the BMJ Publishing Group Limited. For permission to use (where not already granted under a licence) please go to http://group.bmj.com/group/rights-licensing/ permissions 


\section{Tables}

\section{Table 1 | Comparison of diagnostic tests for Giardia42434445464748495051}

\begin{tabular}{|c|c|c|c|c|}
\hline \multirow[t]{2}{*}{$\begin{array}{l}\text { Specimen type by patient } \\
\text { group }\end{array}$} & \multirow[t]{2}{*}{ Usual test (target) } & \multicolumn{2}{|c|}{$\begin{array}{l}\text { Relative diagnostic performance for } \\
\text { Giardia }\end{array}$} & \multirow[t]{2}{*}{ Comments } \\
\hline & & Sensitivity (\%) & Specificity (\%) & \\
\hline \multicolumn{5}{|c|}{ Any patient with community acquired or unexplained diarrhoea } \\
\hline $\begin{array}{l}\text { Most preserved or } \\
\text { unpreserved stool }\end{array}$ & $\begin{array}{l}\text { Ova, cysts, and parasites (OCP) } \\
\text { examination by microscopy of } \\
\text { unconcentrated and concentrated } \\
\text { preparations from which } \\
\text { permanent stained smears can be } \\
\text { made (cysts; trophozoites may be } \\
\text { seen, although some preservatives } \\
\text { may affect their morphology) }\end{array}$ & $31^{*}$ & $100^{*}$ & $\begin{array}{l}\text { May not detect low level, chronic infection. Provides } \\
\text { differential diagnosis of many (but not all) parasites. } \\
\text { Smaller parasites will be missed (eg, Cryptosporidium; } \\
\text { microsporidia). Labour intensive; high level of skill } \\
\text { required; cheap. Most useful where burden of illness } \\
\text { and intensity of infection is high }\end{array}$ \\
\hline $\begin{array}{l}\text { Formalin or SAF preserved } † \\
\text { or unpreserved stool }\end{array}$ & $\begin{array}{l}\text { Enzyme immunoassay (cyst } \\
\text { antigens) }\end{array}$ & $85-100$ & $\geq 95$ & $\begin{array}{l}\text { Only provides diagnosis of specific parasites included } \\
\text { in assay; often in combination with Cryptosporidium } \\
\text { and sometimes Entamoeba histolytica. Useful for high } \\
\text { throughput testing; kit cost maybe offset by use of low }\end{array}$ \\
\hline
\end{tabular}

\begin{tabular}{lll}
\hline $\begin{array}{l}\text { Formalin or SAF preserved } \\
\text { or unpreserved stool }\end{array}$ & Immunochromatographic lateral & 95.8-100 (cyst antigens)
\end{tabular}
skilled staff

\section{or unpreserved stool flow (cyst antigens)}

Formalin or SAF preserved $†$ Immunofluorescent microscopy

or unpreserved stool (cysts)
94-100

100

Only provides diagnosis of specific parasites included in assay. Useful where there is low capacity for complex testing; expensive

Only provides diagnosis of specific parasites included in assay. Useful where other highly sensitive and specific tests are not available, for confirmation of equivocal results, and where the burden and intensity of infection is low. Labour intensive; moderate level of skill required; fluorescent microscope needed; expensive.

\begin{tabular}{llrl}
\hline $\begin{array}{l}\text { Unpreserved stool or only } \\
\text { those in specified }\end{array}$ & $\begin{array}{l}\text { Nucleic acid amplification based } \\
\text { preservativest }\end{array}$ & $90-100$ & $\begin{array}{l}\text { Only provides diagnosis of specific parasites included } \\
\text { in assay. Useful for high throughput testing. Kit cost } \\
\text { maybe offset by decreased staff time. Improves } \\
\text { diagnosis where burden of illness and intensity of } \\
\text { infection is low. Rapidly becomes negative after } \\
\text { successful treatment. Sensitivity and specificity can } \\
\text { vary according to sample processing, amplification } \\
\text { approach, and molecular marker chosen }\end{array}$ \\
\end{tabular}

Patients where Giardia is suspected but not detected in stool

Duodenal or jejunal biopsy Microscopy (trophozoites) or Will probably be supplanted in most cases by sensitive PCR stool assays, but occasionally useful or aspirate collected through nucleic acid amplification based in areas where this and antigen assays are not available

intubation or string test (DNA), flattening of villi (histology)

(Entero-test)

SAF=sodium acetate-acetic acid formalin solution

*Using PCR as reference test. ${ }^{50}$

†Other preservatives may interfere with assay performance. Refer to kit insert. 
Table 2| Current treatment options for Giardia in UK*

\begin{tabular}{lccc} 
Drug & \multicolumn{1}{c}{ Use in pregnancy } & Use in children & Licensed in UK \\
Metronidazole & Avoid first trimester if possible & Yes & Yes \\
\hline Tinidazole & Avoid first trimester if possible & Yes & Yes \\
\hline Albendazole & No & Yes & No \\
\hline Nitazoxanide & No & Yes & No \\
\hline Paromomycin & Yes & Yes & No \\
\hline Mepacrine (quinacrine) & No & No & No
\end{tabular}

*Many are unlicensed in the UK (see text for indications for these in secondary care practice). 


\section{Figures}

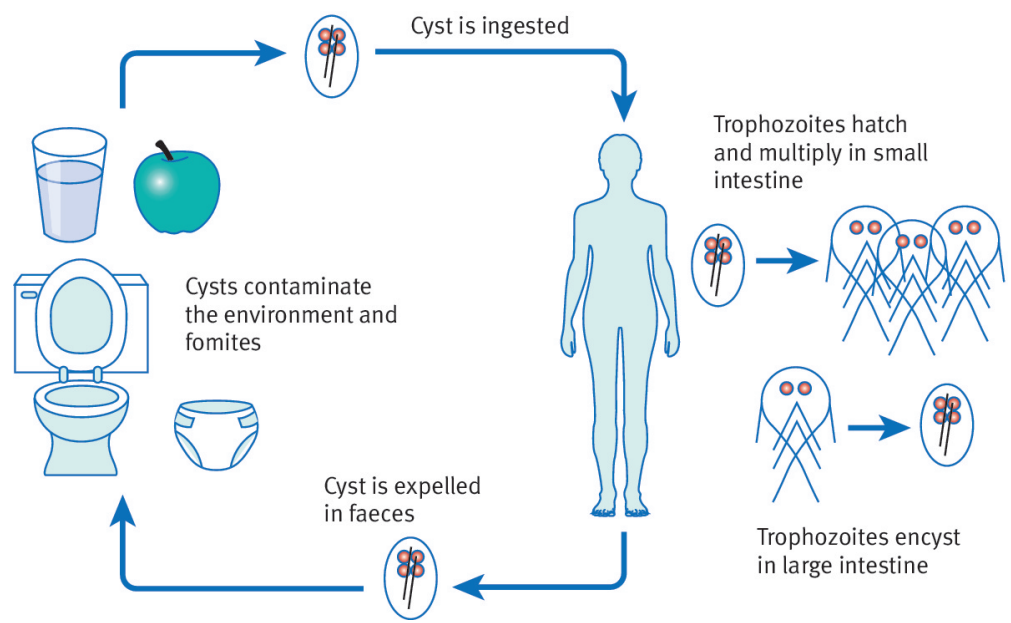

Fig 1 Life cycle and transmission of Giardia

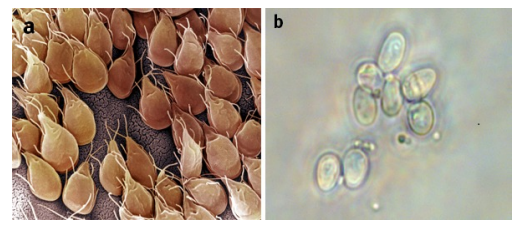

Fig 2 (a) Trophozoites under electron microscopy. (b) Giardia cysts on microscopy 